\title{
Targeting multidrug-resistant ovarian cancer through estrogen receptor a dependent ATP depletion caused by hyperactivation of the unfolded protein response
}

\author{
Xiaobin Zheng ${ }^{1}$, Neal Andruska ${ }^{1,6}$, Michael J. Lambrecht ${ }^{2}$, Sisi $\mathbf{H e}^{3}$, Amadeo \\ Parissenti ${ }^{4}$, Paul J. Hergenrother ${ }^{2}$, Erik R. Nelson ${ }^{3,5}$ and David J. Shapiro ${ }^{1,5,6}$ \\ ${ }^{1}$ Department of Biochemistry University of Illinois, Urbana, IL, USA \\ 2 Department of Chemistry, University of Illinois, Urbana, IL, USA \\ 3 Department of Molecular Integrative Physiology, University of Illinois, Urbana, IL, USA \\ ${ }^{4}$ Cancer Research Program, Advanced Medical Research Institute of Canada, Sudbury, ON, Canada \\ ${ }^{5}$ University of Illinois Cancer Center, Urbana, IL, USA \\ ${ }^{6}$ College of Medicine, University of Illinois, Urbana, IL, USA \\ Correspondence to: David J. Shapiro, email: djshapir@life.illinois.edu \\ Keywords: ERa biomodulator; ATP depletion; unfolded protein response; MDR1/P-glycoprotein/ABCB1; OVCAR-3 ovarian cancer \\ Received: May 02, 2016 Accepted: July 10, 2016 Epub: July 24, 2016 Published: March 13, 2018
}

Copyright: Zheng et al. This is an open-access article distributed under the terms of the Creative Commons Attribution License 3.0 (CC BY 3.0), which permits unrestricted use, distribution, and reproduction in any medium, provided the original author and source are credited.

\section{ABSTRACT}

Ovarian cancers often recur and tumors acquire resistance to chemotherapy due to overexpression of the ATP-dependent efflux pump, multidrug resistance protein 1 (MDR1/P-glycoprotein/ABCB1). Nontoxic small molecule inhibitors targeting MDR1 have remained largely elusive. Instead, in a novel application of our recently described estrogen receptor a (ERa) biomodulator, BHPI, we targeted MDR1's substrate, ATP. BHPI depletes intracellular ATP and nearly blocks MDR1-mediated drug efflux in ovarian cancer cells by inducing toxic hyperactivation of the endoplasmic reticulum stress sensor, the unfolded protein response (UPR). BHPI increased sensitivity of MDR1 overexpressing multidrug resistant OVCAR-3 ovarian cancer cells to killing by paclitaxel by $>1,000$ fold. BHPI also restored doxorubicin sensitivity in OVCAR-3 cells and in MDR1 overexpressing breast cancer cells. In an orthotopic OVCAR-3 xenograft model, paclitaxel was ineffective and the paclitaxel-treated group was uniquely prone to form large secondary tumors in adjacent tissue. BHPI alone strongly reduced tumor growth. Notably, tumors were undetectable in mice treated with BHPI plus paclitaxel. Compared to control ovarian tumors, after the combination therapy, levels of the plasma ovarian cancer biomarker CA125 were at least several hundred folds lower; moreover, CA125 levels progressively declined to undetectable. Targeting MDR1 through UPR-dependent ATP depletion represents a promising therapeutic strategy.

\section{INTRODUCTION}

Ovarian cancer usually presents at an advanced stage and more than half of ovarian cancer patients die within 5 years [1-3]. Although $30-70 \%$ of ovarian tumors are estrogen receptor $\alpha(E R \alpha)$ positive, endocrine therapy is largely ineffective [4-6]. Recurrent ovarian tumors are therefore treated with chemotherapy. Although initially responsive, after several cycles of treatment tumors often recur as resistant ovarian cancer, with few therapeutic options [7]. In ovarian cancer, the most common mechanism for resistance to paclitaxel and other chemotherapeutic agents is overexpression of ATPdependent membrane efflux pumps of the $\mathrm{ABC}$ transporter family, especially Multidrug Resistance Protein 1 (MDR1)/P-glycoprotein/ABCB1 [8-13]. MDR1-mediated efflux reduces intracellular drug concentrations to levels at which the drugs are no longer effective at doses patients can tolerate $[8,12,13]$. Despite intensive efforts, clinically effective non-toxic small molecule MDR1 inhibitors have not been described [14]. Instead of inhibition of MDR1 
we target its substrate, ATP. MDR1-mediated efflux is exquisitely sensitive to reductions in ATP levels [15-17]. However, selective depletion of ATP in cancer cells has been little studied and is difficult to achieve.

We recently described the novel non-competitive estrogen receptor $\alpha(E R \alpha)$ biomodulator, BHPI, which is effective in models of $E R \alpha^{+}$breast cancer [18]. In cancer cells, BHPI, acting via ER $\alpha$, induces sustained toxic hyperactivation of the endoplasmic reticulum (EnR) stress sensor, the unfolded protein response (UPR) [18]. The UPR consists of three main branches that together balance the synthesis of new proteins with the availability of chaperones and other proteins to help fold and transport proteins within cells $[19,20]$. In the classical reactive mode, EnR stress resulting from accumulation of unfolded or misfolded protein, or other stresses, triggers UPR activation [19-21]. In the recently unveiled anticipatory mode of UPR activation, estrogen or other mitogenic hormones pre-activate the UPR and anticipate a future need for increased protein folding capacity $[22,23]$. BHPI distorts this normal anticipatory pathway by binding to a different site on ER $\alpha$ than estrogens and inducing a different ER $\alpha$ conformation [18]. This enables BHPI to act through ER $\alpha$ to hyperactivate the UPR, converting it from protective to toxic [18]. BHPI strongly activates phospholipase $\mathrm{C} \gamma(\mathrm{PLC} \gamma)$, producing inositol triphosphate $\left(\mathrm{IP}_{3}\right)$, which binds to and opens endoplasmic reticulum $\mathrm{IP}_{3}$ Receptor $\left(\mathrm{IP}_{3} \mathrm{R}\right)$ calcium channels allowing rapid efflux of calcium from the lumen of the EnR into the cytosol.

Intracellular calcium levels are tightly regulated by EnR transport channels and pumps [24, 25]. Opening the $\mathrm{IP}_{3} \mathrm{Rs}$ and ryanodine receptor (RyR) calcium channels allows efflux of the high concentrations of $\mathrm{Ca}^{2+}$ stored in the lumen of the EnR into the cytosol [26-28]. To produce this concentration gradient, powerful ATP-dependent sarcoplasmic/endoplasmic reticulum calcium-ATPase (SERCA) pumps in the EnR membrane pump calcium from the cytosol into the EnR lumen [29-31]. We show that BHPI elicits a sustained, $\mathrm{IP}_{3} \mathrm{R}$ dependent, increase in cytosol calcium in ovarian cancer cells. Since the $\mathrm{IP}_{3} \mathrm{R}$ calcium channels remain open after BHPI treatment, the calcium pumped into the EnR by the ATP-dependent SERCA pumps rapidly leaks back out. We hypothesized that sustained BHPI hyperactivation of the UPR creates a futile cycle depleting intracellular ATP, and this ATP depletion might provide a novel way to inactivate MDR1.

Using cell-based and in vivo studies we evaluated the potential of this novel approach to restoring chemosensitivity of multidrug resistant ovarian tumors. Notably, in OVCAR-3 ovarian cancer cells, which are resistant to micromolar paclitaxel, BHPI restored sensitivity to therapeutically relevant low nanomolar concentrations of paclitaxel. We preformed what is perhaps the first orthotopic intra-ovarian mouse xenograft study using multidrug resistant OVCAR-3 cells. Surprisingly, paclitaxel was both ineffective and actually appeared to promote metastases, a result not seen in the other treatment groups. Notably, no ovarian tumors were detected in any of the mice treated with BHPI plus paclitaxel. Moreover, levels of the circulating ovarian cancer marker, CA125/ mucin 16 , declined from $\sim 700$ units $/ \mathrm{ml}$ in control vehicletreated mice to undetectable in all of the BHPI plus paclitaxel treated mice.

\section{RESULTS}

\section{BHPI induces a sustained increase in intracellular calcium through activation of the ERo-PLC $\gamma$ - $I_{3} R$ pathway}

Using breast cancer cells, we previously showed $\mathrm{E}_{2}-$ $\mathrm{ER} \alpha$ activates a $\mathrm{PLC} \gamma$-IP $\mathrm{R}$ pathway to release calcium from EnR stores into the cytosol [32]. Activated PLC $\gamma$ cleaves its substrate to produce $\mathrm{IP}_{3}$. The non-competitive $\mathrm{ER} \alpha$ biomodulator BHPI, that works by hyperactivating the UPR, produces much higher levels of $\mathrm{IP}_{3}$ than $\mathrm{E}_{2}$ [18]. If we were to use this pathway to target multidrug resistant ovarian cancer, we had to first show that the pathway functions in ovarian cancer cells. We initially quantitated $\mathrm{IP}_{3}$ levels in $\mathrm{ER}^{+} \mathrm{PEO}-4$ ovarian cancer cells treated with $\mathrm{E}_{2}$ or BHPI. $\mathrm{E}_{2}$ induced a modest increase in $\mathrm{IP}_{3}$ levels, while BHPI induced a much more robust 6-fold increase (Figure 1A).

To test whether $\mathrm{E}_{2}$ and BHPI rapidly increase cytosolic $\mathrm{Ca}^{2+}$, we monitored calcium levels using the fluorescent calcium sensor dye Fluo-4 AM. In $<1$ min., $\mathrm{E}_{2}$ and BHPI increased cytosol $\mathrm{Ca}^{2+}$ in PEO-4 cells (Figure 1B, 1C). Notably, in the absence of extracellular calcium, $\mathrm{E}_{2}$ elicited a transient $\sim 3.5$ fold increase in cytosolic $\mathrm{Ca}^{2+}$ with the $\mathrm{Ca}^{2+}$ signal rapidly returning to the basal level (Figure 1B and Supplementary Movie 1). In contrast, BHPI elicited a sustained $\sim 7$ fold increase in cytosolic $\mathrm{Ca}^{2+}$ (Figure 1C and Supplementary Movie 2). Since pretreatment with the PLC $\gamma$ inhibitor U73122 abolished the calcium release observed with $\mathrm{E}_{2}$ or BHPI, PLC $\gamma$ activation was required for the increase in cytosolic $\mathrm{Ca}^{2+}$ (Figure 1B, 1C and Supplementary Figure 1). BHPI induced a large increase in cytosolic $\mathrm{Ca}^{2+}$ even in the absence of extracellular $\mathrm{Ca}^{2+}$, indicating that BHPI increases cytosolic $\mathrm{Ca}^{2+}$ by depleting the $\mathrm{Ca}^{2+}$ store in the EnR. Supporting this idea is our observation that inhibiting the IP $\mathrm{R} \mathrm{Ca}^{2+}$ channel with 2-APB abolished the rapid $\mathrm{E}_{2}$ and $\mathrm{BHPI}$ stimulated $\mathrm{Ca}^{2+}$ release (Figure 1B, $1 \mathrm{C}$ and Supplementary Figure 1). In contrast, inhibition of RyR calcium channels with high concentration ryanodine (Ry) did not block $\mathrm{E}_{2}$ or BHPI stimulated $\mathrm{Ca}^{2+}$ release in PEO-4 cells (Figure 1B, 1C). Confirming BHPI's structural specificity and the requirement for $E R \alpha$, a control compound, $\mathrm{C} 8$, that is structurally related to BHPI, but does not bind ER $\alpha$ in vitro [18], failed to increase 
cytosolic $\mathrm{Ca}^{2+}$ (Figure 1C). These results demonstrate that BHPI strongly activates the ER $\alpha$-PLC $\gamma$-IP 3 R pathway in ovarian cancer cells, resulting in a sustained increase in cytosolic $\mathrm{Ca}^{2+}$.

\section{BHPI activates the UPR in ovarian cancer cells}

Efflux of calcium stored in the lumen of the EnR into the cell body activates the UPR. The core UPR signaling cascade consists of 3 EnR sensors whose activation increases protein-folding capacity and temporarily reduces protein production (Supplementary Figure 1). Activation of IRE1 $\alpha$, which alternatively splices the transcription factor XBP1, produces the widely used UPR marker, active spliced XBP1 (sp-XBP1) [33]. Supporting activation of the IRE $1 \alpha$ branch of the UPR, in PEO-4 ovarian cancer cells, BHPI and $\mathrm{E}_{2}$ robustly induced sp-XBP1 (Figure 2A and Supplementary Figure $2 \mathrm{~A})$. Protein synthesis is regulated by autophosphorylation of PERK [34]. Phosphorylated PERK (p-PERK) phosphorylates of eukaryotic initiation factor $2 \alpha(\mathrm{eIF} 2 \alpha)$, which leads to transient inhibition of protein synthesis (Supplementary Figure 1). $\mathrm{E}_{2}$ induced a weak and transient phosphorylation of eIF $2 \alpha$ in ovarian cells (Supplementary Figure 2B), while BHPI elicited robust phosphorylation of PERK and eIF2 $\alpha$ (Figure 2B, 2C), resulting in inhibition of most protein synthesis (Figure 2D) and a decline in total PERK and eIF2 $\alpha$ protein (Figure 2B, 2C). Consistent with their inhibitors' ability to block calcium efflux (Figure 1B, 1C), inhibition of PLC $\gamma$ with U73122 and locking the $\mathrm{IP}_{3} \mathrm{R}$ calcium channels with 2-APB, but not inhibition of the RyR calcium channels, reversed BHPI inhibition of protein synthesis (Figure 2E). EnR stress leads to proteolytic cleavage of ATF $6 \alpha$ to active $50 \mathrm{kDa}$ ATF6 $\alpha$ (p50-ATF6 $\alpha$ ) (Supplementary Figure 1) [35]. Demonstrating BHPI and $\mathrm{E}_{2}$ activate the ATF $6 \alpha$ arm of UPR, $E_{2}$ and BHPI increased p50-ATF6 $\alpha$ levels in PEO-4 cells (Figure 2F and Supplementary Figure 2C). Active p50-ATF $6 \alpha$ increases production of BiP/GRP78/HSPA5
A

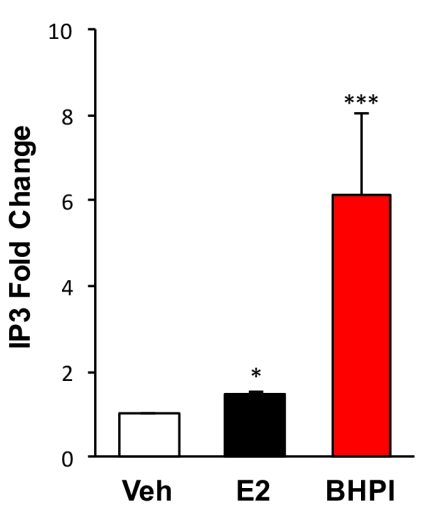

B
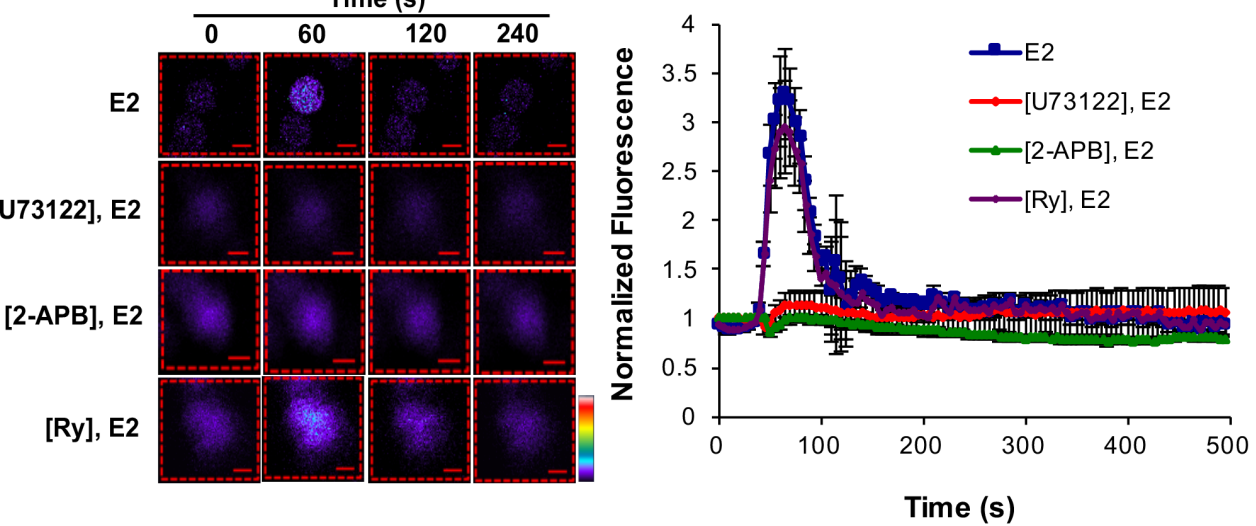

C
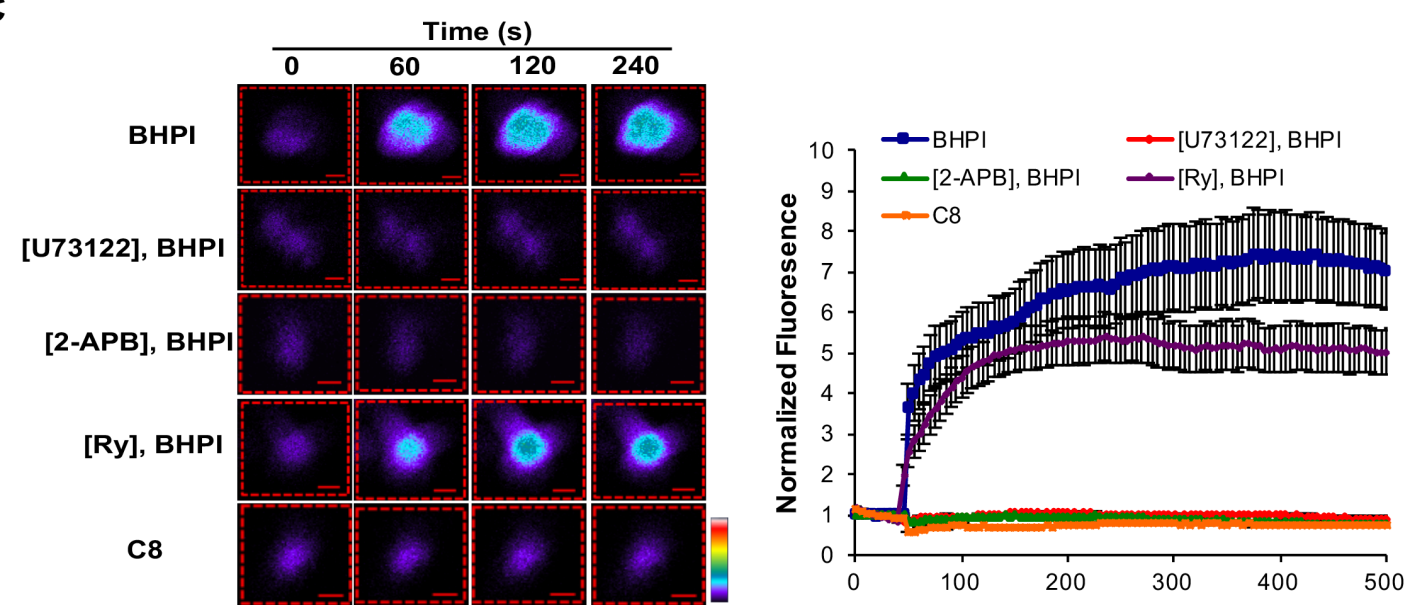

Figure 1: BHPI and estrogen stimulate release of calcium from the endoplasmic reticulum into the cytosol. A. Quantitation of intracellular IP ${ }_{3}$ levels after 10 min treatment with DMSO, $17 \beta$-estradiol $\left(\mathrm{E}_{2}\right)$, or BHPI in PEO-4 ovarian cells $(n=3)$. B., C. Estrogen and BHPI increase cytosol calcium levels. Visualization of cytosolic $\mathrm{Ca}^{2+}$ using Fluo-4 AM; estrogen or BHPI was added to PEO-4 cells at $50 \mathrm{~s}$. Color scale from basal $\mathrm{Ca}^{2+}$ to highest $\mathrm{Ca}^{2+}$ : purple, blue, green, yellow, red, white. Quantitation of cytosolic $\mathrm{Ca}^{2+}$ levels after pretreating PEO-4 cells with U73122, 2-APB, or Ry followed by treatment with estrogen or BHPI $(n=12-20)$. Concentrations: U73122, $1 \mu \mathrm{M}$; 2-APB, $100 \mu \mathrm{M}$; Ry, C8, $10 \mu \mathrm{M}$; E $2,200 \mathrm{nM}$; BHPI, $10 \mu \mathrm{M}$. $* P<0.05,{ }^{* * *} P<0.001$. 
and other EnR chaperones [35]. BHPI and $\mathrm{E}_{2}$ increased production of BiP mRNA in PEO-4 ovarian cancer cells (Figure 2G and Supplementary Figure 2D). However, since BHPI inhibited protein synthesis (Figure 2D and $2 \mathrm{E})$, BiP protein levels were reduced in BHPI-treated PEO-4 cells (Figure 2H).

Collectively, our findings in ovarian cancer cells indicate that $\mathrm{E}_{2}-\mathrm{ER} \alpha$ induces weak and transient anticipatory activation of the UPR and that BHPI distorts this UPR pathway resulting in strong and sustained UPR activation. These data provide a potential mechanism for inactivating MDR1 in ovarian cancer cells.

\section{BHPI depletes intracellular ATP inactivating MDR1-mediated efflux}

We hypothesize: (i) In response to the BHPImediated loss of EnR calcium, SERCA pumps will carry out ATP-dependent transport of $\mathrm{Ca}^{2+}$ from the cytosol back into the lumen of the EnR. (ii) Since BHPI elicits sustained increases in cytosolic $\mathrm{Ca}^{2+}$ (Figure 1C, Video 2), indicating the $\mathrm{IP}_{3} \mathrm{R}$ calcium channels remain open, calcium pumped from the cytosol into the lumen of the EnR leaks back out through the open $\mathrm{IP}_{3} \mathrm{R}$ channels, creating a futile cycle that depletes ATP (Figure 3A). To test our hypothesis we investigated the effect of BHPI on ATP levels in ovarian cancer cells. BHPI treatment rapidly reduced intracellular ATP levels in ER $\alpha^{+}$PEO-4 and OVCAR-3 ovarian cancer cells (Figure 3B, 3C). Supporting the role of the EnR SERCA pumps in ATP depletion, the SERCA pump inhibitor, thapsigargin (THG) blocked the decline in ATP levels seen after BHPI treatment (Figure 3B, 3C).

$\mathrm{ER} \alpha^{+}$, multidrug resistant, OVCAR-3 ovarian cancer cells were derived from a patient whose cancer recurred after surgery and multiple rounds of chemotherapy [36]. OVCAR-3 cells have been propagated without cloning and therefore retain much of the diversity of a patient derived xenograft $[36,37]$. ER $\alpha^{+} \mathrm{MCF}-7$ breast cancer cells are normally MDR1 negative and sensitive to the chemotherapy agent doxorubicin. MCF-7 doxorubicin $\left(\mathrm{MCF}-7_{\mathrm{dox}}\right)$ resistant breast cancer cells were generated by selection in increasing doxorubicin concentrations $[38,39]$. Confirming that upregulation of MDR1 is a common mechanism in cancer cells resistant to cytotoxic chemotherapy, both the MCF-7 ${ }_{\text {dox }}$ and OVCAR-3 cells overexpress MDR1 (Figure 3D). Notably, while $50 \mathrm{nM}$ BHPI blocked MCF-7 proliferation, $500 \mathrm{nM}$ BHPI was required to block proliferation of the $\mathrm{MCF}-7_{\text {dox }}$ breast cancer cells (Supplementary Figure 3A, 3B). This is consistent with the possibility that BHPI may be an MDR1 substrate.
A

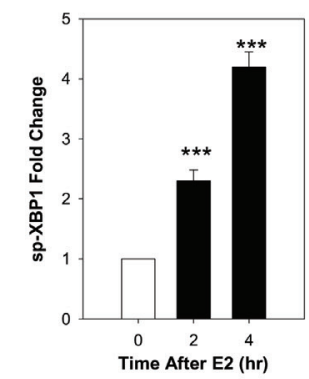

E

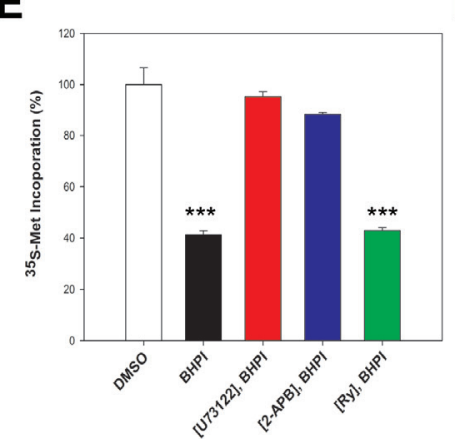

B

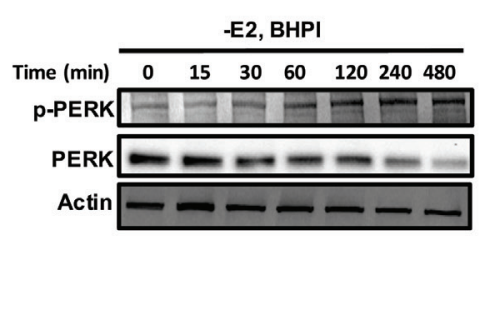

$\mathbf{F}$
C

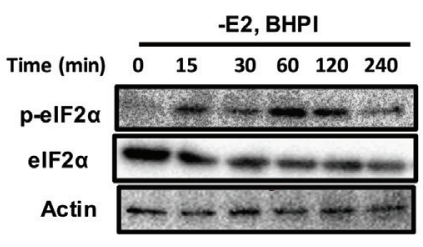

G

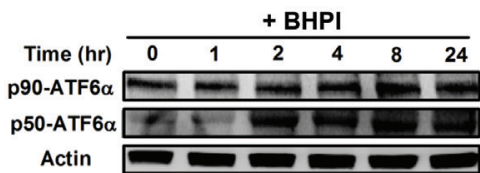

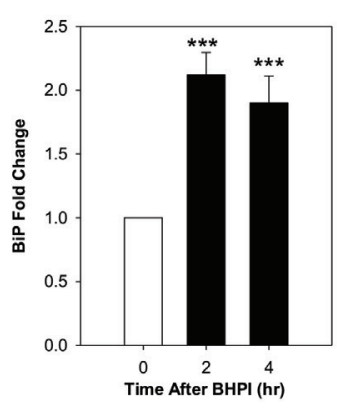

D

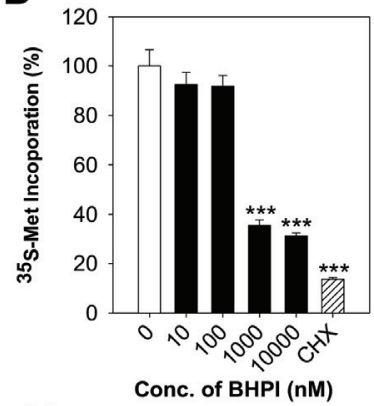

H

Conc. of BHPI (nM)

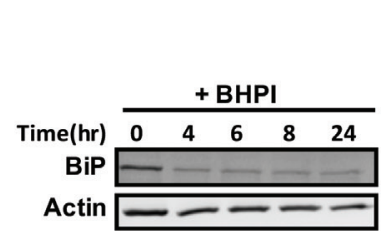

Figure 2: In PEO-4 ovarian cells, BHPI activates the three branches of the UPR and inhibits protein synthesis. A. qRTPCR analysis showing the increased level of spliced XBP1 (sp-XBP1) mRNA $(n=3)$. B., C. Western blot analysis showing time dependent phosphorylation of PERK and eIF2 $\alpha$. D. Protein synthesis after treating the cells with increasing concentrations of BHPI $(n=4)$. CHX, cycloheximide. Protein synthesis from DMSO treated control cells was set to $100 \%$. E. The level of protein synthesis after pretreating the cells with either the inhibitors U73122, 2-APB, or Ry followed by BHPI treatment $(n=4)$. F. Western blot analysis shows full-length (p90ATF6 $\alpha$ ) and cleaved p50-ATF6 $\alpha$ in BHPI treated cells. Effect of BHPI on the level of BiP mRNA level G. and protein H.. Concentrations: $\mathrm{U} 73122,1 \mu \mathrm{M}$; 2-APB, $100 \mu \mathrm{M}$; BHPI, $500 \mathrm{nM}$ (E) or $1 \mu \mathrm{M}$ (other panels). $* * * P<0.001$. 
The fluorescent MDR1 substrate Rhodamine 123 (Rho-123) is widely used to quantitate MDR1-mediated efflux from cells into the medium [14, 40]. OVCAR-3 and $\mathrm{MCF}-7_{\text {dox }}$ cells that overexpress MDR1, and control MDR1 negative PEO-4 cells were preloaded with Rho123 and Rho-123 efflux into the medium was quantitated. Rho-123 efflux from the MDR1 negative PEO-4 cells was negligible (Supplementary Figure 4). OVCAR-3 and MCF-7 ${ }_{\text {dox }}$ cells exhibited robust time-dependent efflux of Rho-123 (Supplementary Figure 4). We tested whether BHPI-treatment, which reduces intracellular ATP levels, inhibits MDR1-mediated Rho-123 efflux. In OVCAR-3 and MCF-7 Dox cells BHPI nearly abolished Rho-123 efflux (Figure 3E, 3F). Consistent with the proposed futile cycle leading to ATP depletion causing inhibition of MDR1-mediated efflux (Figure 3A), inhibiting the rise in intracellular $\mathrm{Ca}^{2+}$ by either inhibiting PLC $\gamma$ with U73122, or by locking the EnR IP ${ }_{3} \mathrm{R}$ calcium channels closed with 2-APB (Figure 1C), reversed BHPI inhibition of MDR1mediated efflux (Figure 3E, 3F). We next explored whether other actions of BHPI might complement ATP depletion and contribute to the near abolition of MDR1-mediated efflux.

In OVCAR-3 cells, BHPI elicited strong and sustained activation of the PERK arm of the UPR inhibiting protein synthesis cells by $\sim 60 \%$ (Figure $4 \mathrm{~A}$ ). This reduced production of protein led to an $\sim 2$ fold decline in MDR1 levels (Figure 4B). Therefore, the reduced level of MDR1 and the decline in the level of its substrate ATP, work together to enable BHPI to nearly abolish MDR1-mediated efflux. We therefore tested whether BHPI could restore sensitivity of OVCAR-3 and $\mathrm{MCF}-7_{\text {dox }}$ cells to therapeutically relevant concentrations of chemotherapy drugs.

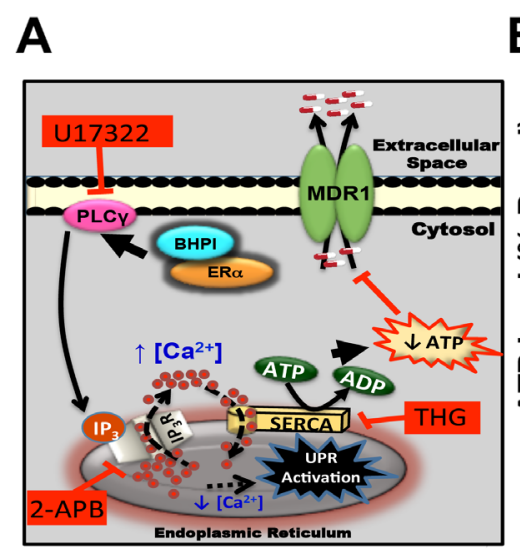

D

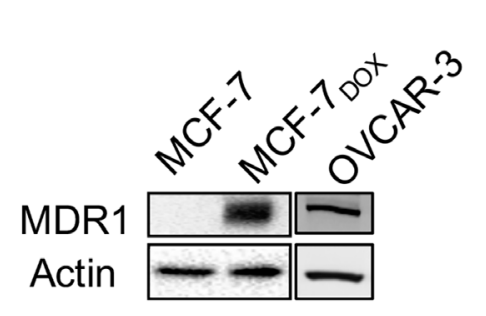

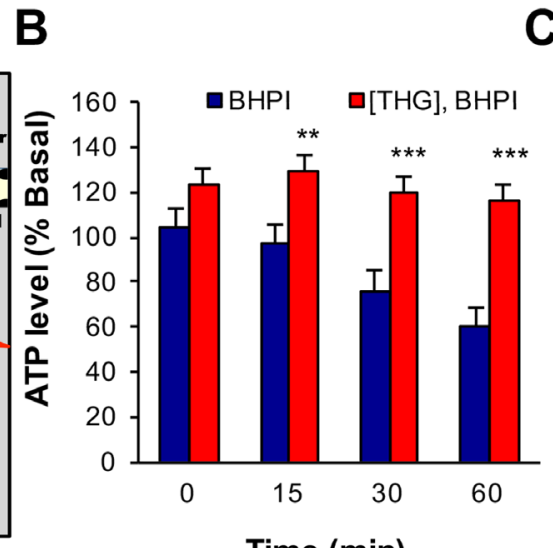

Time (min)

E

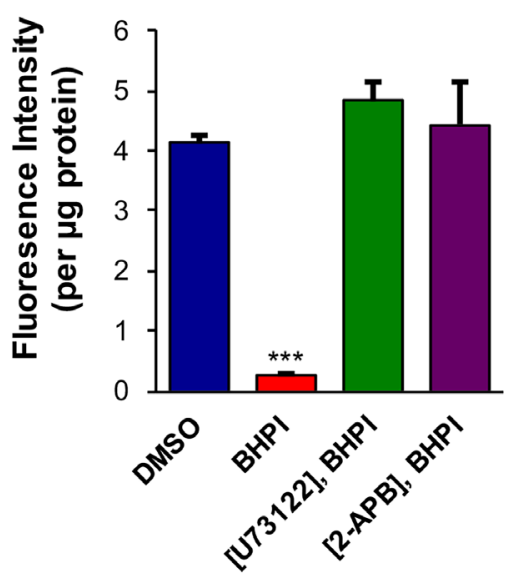

C

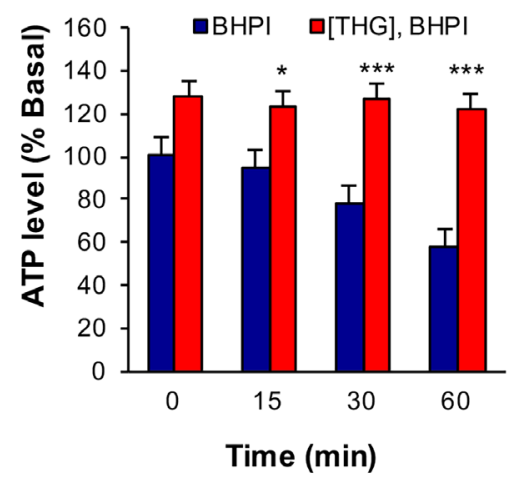

$\mathbf{F}$

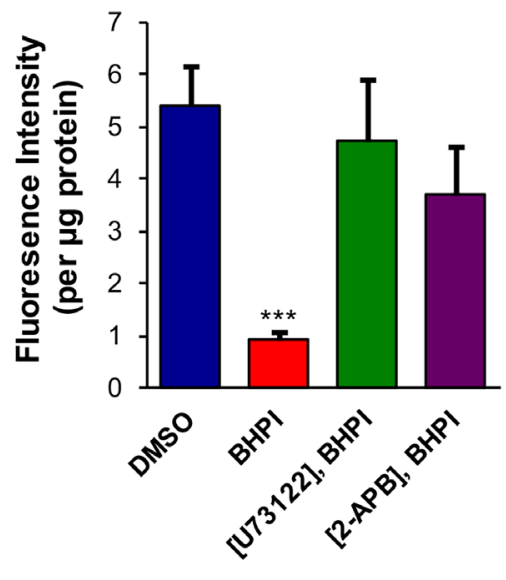

Figure 3: In MDR1 overexpressing cells, BHPI depletes intracellular ATP and inhibits MDR1 efflux activity. A. Proposed model of the pathway by which BHPI inactivates MDR1. B., C. Intracellular ATP quantitation showing effect of BHPI on cellular ATP level after pretreating cells with either DMSO or thapsigargin (THG) $(n=6)$. D. Western blot analysis showing MDR1 protein level from the indicated cell lines. E., F. Rhodamine-123 (Rho-123) quantitation showing the effect of BHPI on Rho-123 concentration in the media after pretreating cells with either DMSO, U73122, or 2-APB $(n=6)$. Concentrations: U73122, $1 \mu \mathrm{M} ; 2-\mathrm{APB}, 100 \mu \mathrm{M} ; \mathrm{BHPI}, 1 \mu \mathrm{M}(\mathrm{B}, \mathrm{C})$ or $500 \mathrm{nM}(\mathrm{E}, \mathrm{F})$. Data is the mean \pm SEM. $* * * P<0.001$. 


\section{BHPI resensitizes resistant cancer cells to paclitaxel and doxorubicin}

OVCAR-3 cells were highly resistant to paclitaxel, and were not killed, even at $10,000 \mathrm{nM}$ paclitaxel (Figure 5A). While BHPI alone blocked OVCAR-3 cell growth, it was not cytotoxic. BHPI restored the cytotoxicity of paclitaxel at $10 \mathrm{nM}$ paclitaxel, reducing the number of OVCAR-3 cells by $\sim 70 \%$ in two days (Figure 5A). This represents an $>1,000$ fold increase in sensitivity to paclitaxel. Furthermore, OVCAR-3 cells were also resistant to $1,000 \mathrm{nM}$ doxorubicin; BHPI also restored sensitivity to doxorubicin (Figure 5B). MCF- $7_{\text {dox }}$ breast cancer cells were resistant to $250 \mathrm{nM}$ doxorubicin. BHPI restores sensitivity of the MCF-7 cells, to the lowest dose of doxorubicin tested $(15 \mathrm{nM})$ (Figure 5C). Importantly, since the therapeutic range of concentrations is $\sim 15-20 \mathrm{nM}$ for paclitaxel and $100-150$ $\mathrm{nM}$ for doxorubicin [37, 41, 42], BHPI restored sensitivity of multidrug resistant ovarian and breast cancer cells to therapeutically relevant concentrations of paclitaxel and doxorubicin.

We propose that BHPI restores drug sensitivity because it strongly activates the ER $\alpha$-PLC $\gamma$-IP ${ }_{3} \mathrm{R}$ pathway leading to ATP depletion and a moderate reduction in MDR1 expression. A testable alternative is that the BHPI-mediated $>1,000$ fold increase in sensitivity of OVCAR-3 cells to killing by paclitaxel is simply due to combinatorial actions of two toxic drugs, BHPI and paclitaxel. OVCAR-3 cells are also resistant to cisplatin, which is not a substrate of MDR1 and is therefore not pumped out by MDR1 [43]. BHPI treatment did not restore sensitivity of OVCAR-3 cells to killing by cisplatin (Supplementary Figure 5A). Thus, BHPI's ability to abolish multidrug resistance is due to its ability to interfere with MDR1, and not to the additive effects of BHPI in combination with a chemotherapeutic. Consistent with BHPI acting through ER $\alpha$, BHPI did not inhibit proliferation or restore paclitaxel sensitivity in ER $\alpha$ negative MDR1 overexpressing NIH/ADRes ovarian cancer cells (Supplementary Figure 5B). In addition, the inactive structural relative of BHPI, $\mathrm{C} 8$, did not restore paclitaxel or doxorubicin sensitivity in OVCAR-3 cells (Supplementary Figure 5C).

We next sought to confirm that the ability of BHPI to resensitize OVCAR-3 cells to paclitaxel was mediated by the PLC $\gamma$ pathway. Although useful in short-term studies, the long-term use of PLC $\gamma$ and $\mathrm{IP}_{3} \mathrm{R}$ inhibitors U73122 and 2-APB may result in secondary effects. Since simultaneous knockdown of the three $\mathrm{IP}_{3} \mathrm{R}$ channels is somewhat toxic [18], it cannot be combined with the two other drugs. We therefore evaluated the effect of siRNA knockdown of PLC $\gamma$ on paclitaxel sensitivity in BHPItreated OVCAR-3 cells. siRNA knockdown of PLC $\gamma$, but not a control siRNA, abolished BHPI-mediated restoration of paclitaxel sensitivity (Figure 5D, 5E). Thus, BHPI's novel mechanism of action leads to inactivation of MDR1 in multiple cell models, resulting in restoration of sensitivity to therapeutically relevant concentrations of paclitaxel and doxorubicin.

\section{BHPI restores paclitaxel sensitivity and eliminates tumors in a multidrug resistant ovarian tumor model}

To assess in vivo effectiveness of BHPI in restoring drug sensitivity, we used OVCAR-3 cells, which are resistant to therapeutically relevant concentrations of all

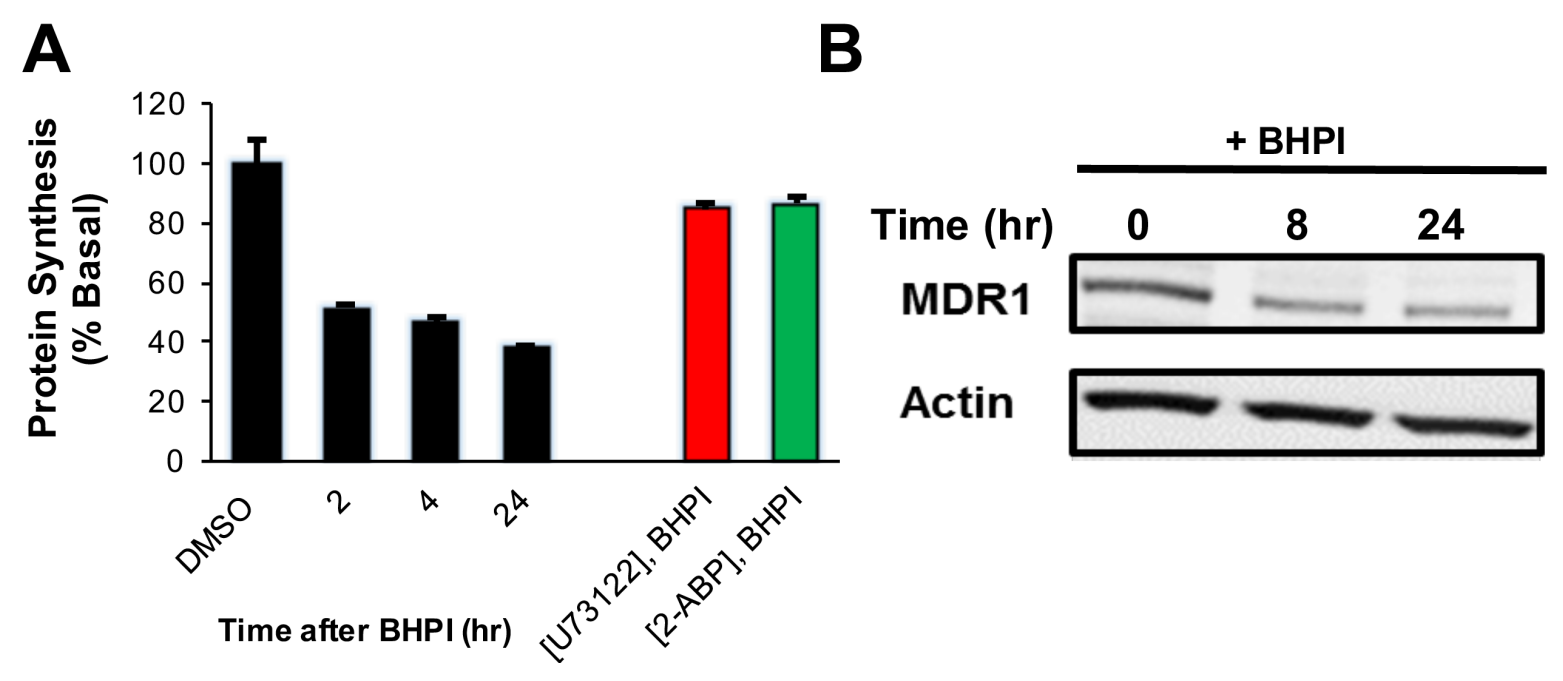

Figure 4: BHPI inhibits protein synthesis and reduces the level of MDR1 protein in OVCAR-3 cells. A. Protein synthesis was measured using the incorporation of ${ }^{35} \mathrm{~S}$ methionine into protein at the indicated times after pretreating cells for 20 min. with either DMSO, U73122, or 2-APB $(n=4)$. B. Western blot indicating the MDR1 protein level at indicated time points after BHPI treatment. Concentrations: U73122, $1 \mu \mathrm{M}$; 2-APB, $100 \mu \mathrm{M}$; BHPI, $500 \mathrm{nM}$ (A) or $1 \mu \mathrm{M}$ (B) . Data is the mean \pm SEM. 
common anticancer drugs [36]. We used an orthotopic model in which OVCAR-3 cells were grafted into the bursa of one ovary, the other ovary serving as a control. At the end of the 10 week study, ovarian tumors were evident in each of the vehicle-treated mice, with an average weight of $200 \mathrm{mg}$ (Figure 6A AND Supplementary Figure 6). Surprisingly, in the paclitaxel-treated group there were large secondary tumors in adjacent tissue (Supplementary Figure 6). Increased metastasis of paclitaxel-treated OVCAR-3 tumors has not been previously described because this is perhaps the first use of OVCAR-3 cells in an orthotopic ovarian model [44]. BHPI alone very significantly reduced tumor size and weight (Figure 6A and Supplementary Figure 6). Notably, there were no visible OVCAR-3 ovarian tumors in the combined BHPI and paclitaxel treatment group and no secondary tumors were detected (Figure 6A and Supplementary Figure 6). In the BHPI plus paclitaxel group, the ovary injected with OVCAR-3 cancer cells and the control ovary appeared identical.

Although tumors were not visible in the BHPI plus paclitaxel group, to more sensitively assess whether tumor cells were still present, we quantified the circulating level of serum CA125 tumor antigen. In ovarian cancer, the circulating level of CA125 is a widely used biomarker for therapeutic progress and tumor recurrence [45-47]. Although the basal level of CA125 in normal human serum is $\sim 35 \mathrm{U} / \mathrm{ml}$ (Figure 6B, dashed line), the human CA125 antibody does not cross-react with control mouse serum. Thus, the level of serum CA125 is a sensitive marker for the survival of human OVCAR-3 cancer cells in the mice. Serum samples were taken in weeks 7-10 of the study and assayed after completion of the study. CA125 levels in the control vehicle-treated group and in the paclitaxel-treated group increased dramatically in weeks 7-10. Confirming that the OVCAR-3 tumors are highly paclitaxel-resistant, CA125 levels were similar in the control vehicle-treated and paclitaxel-treated mice (Figure 6B). BHPI strongly reduced circulating CA125 levels compared to vehicle or paclitaxel alone, but CA125 levels rise slightly from weeks 7-10 (Figure 6B, green line). Strikingly, in the BHPI plus paclitaxel treated mice, CA125 levels declined from a low starting level of $\sim 30 \mathrm{U} / \mathrm{ml}$ at week 7 to concentrations below the detection limits for all five mice at week 10 (Figure 6B, purple line). Since the detection limit of the assay is $\pm 5 \mathrm{U} / \mathrm{ml}$ and the vehicle-treated group had circulating CA125 levels of $\sim 700 \mathrm{U} / \mathrm{ml}$, tumor burden was reduced by 200 fold or more in mice to undetectable levels after combined BHPI and paclitaxel treatment. Measurement of mouse body weights throughout the study
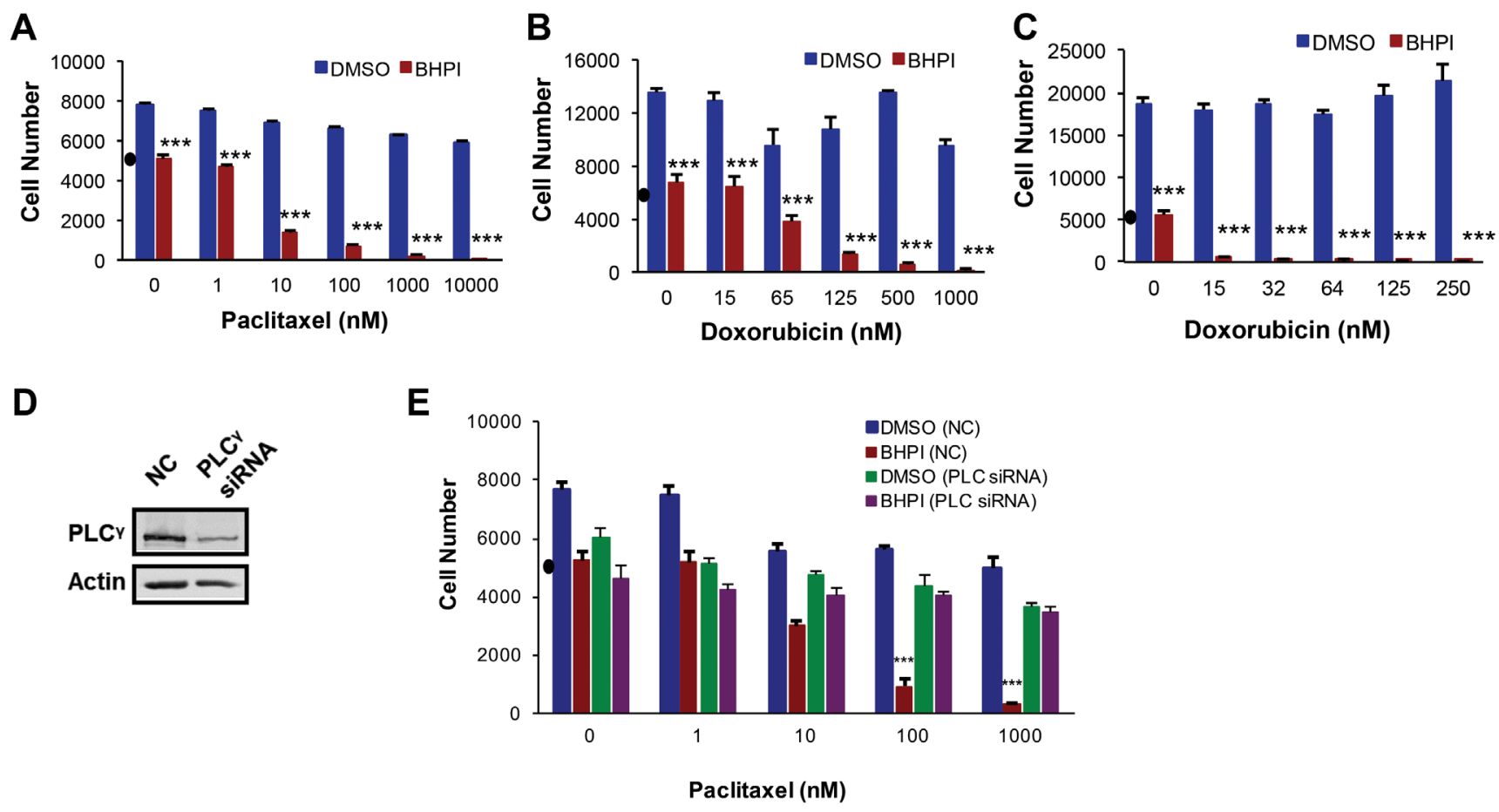

Figure 5: BHPI restores drug sensitivity in MDR1 overexpressing cells. MTS assays showing the effect of BHPI (1 $\mu$ M) plus either DMSO or the indicated concentrations of paclitaxel A. or doxorubicin B. in OVCAR-3 ovarian cells $(n=6)$ or doxorubicin in MCF$7_{\text {dox }}$ breast cells C. $(n=6)$. D. Western blot analysis showing the PLC $\gamma$ protein level after transfecting the cells with either non-coding SmartPool siRNA or $100 \mathrm{nM}$ SmartPool PLC $\gamma$ siRNA. E. PLC $\gamma$ knockdown abolishes the ability of BHPI to reverse multidrug resistance. OVCAR-3 cells were transfected with either non-coding control or PLC $\gamma$ siRNA and the effect on cell number in cells treated with vehicle of BHPI was determined $(n=6)$. Cell number in a-e is from standard curves of absorbance versus cell number for each cell line. "•" on each graph denotes the number of cells at the start of the experiments. Data is the mean \pm SEM. $* * * P<0.001$. 
suggested that BHPI alone and BHPI plus paclitaxel were well tolerated and no visible toxic effects of BHPI were seen in the mice (Supplementary Figure 7).

\section{DISCUSSION}

Although $30-70 \%$ of ovarian cancers are $\mathrm{ER}^{+}$at diagnosis, endocrine therapy is largely ineffective [1-3]. The failure of endocrine therapy raises the possibility that the presence or absence of ER $\alpha$ has little effect on ovarian tumors and there is no selection pressure to maintain ER $\alpha$ in recurrent multidrug resistant tumors. However, recent studies show that estrogens, acting through ER $\alpha$, enhance ovarian tumor growth and increase risk of lymphovascular space invasion [48, 49]. Moreover, ER $\alpha$ expression correlates with poor clinical outcome in ovarian cancer [50]. The association of ER $\alpha$ with late-stage therapyresistant tumors strongly suggests that $\mathrm{ER} \alpha$ is maintained in many of these tumors, making them targetable with our small molecular biomodulator.

Therapeutic options are limited for patients with recurrent multidrug resistant ovarian cancer. Overexpression of MDR1 is a major resistance mechanism $[8,13,14]$. Selective non-toxic inhibitors of MDR1 have proven difficult to identify. For MDR1 inhibitors, toxicity due to inhibition of $\mathrm{ABC}$ transporter family members in normal cells has been a serious concern [8].
BHPI is effective because it uses a therapeutic strategy different from classic MDR1 inhibitors and most other cytotoxic chemotherapeutic drugs [8, 14]. It works by hyperactivating the UPR, a pathway that is already partially activated as a protective mechanism in tumor cells. We recently reported that elevated expression of a UPR gene signature consisting of UPR sensors and downstream targets of UPR activation is tightly correlated with therapy resistance, tumor recurrence and a poor prognosis in $\mathrm{ER} \alpha^{+}$breast cancer [32]. In contrast, the UPR is nearly off in normal healthy cells and its components are not overexpressed [32]. Consistent with this, BHPI was well tolerated in the xenograft study. While BHPI and estrogen share a common ER $\alpha$-dependent pathway for UPR activation (Supplementary Figure 1), the weak estrogen-ER $\alpha$ activation of the UPR induces protective chaperones and is important for subsequent estrogenER $\alpha$ activation of gene expression and induction of cell proliferation [32]. Notably, BHPI binding to ER $\alpha$ is not competitive with estrogen binding, indicating that they bind ER $\alpha$ at different sites [18]. Moreover, BHPI induces conformational changes in $\mathrm{ER} \alpha$ not seen with estrogen [18]. Thus, unlike estrogen, BHPI hyperactivates the UPR, leading to persistent inhibition of protein synthesis in ER $\alpha$ positive cancer cells [18].

Strong and sustained activation of the UPR by BHPI creates a futile cycle leading to depletion of intracellular
A

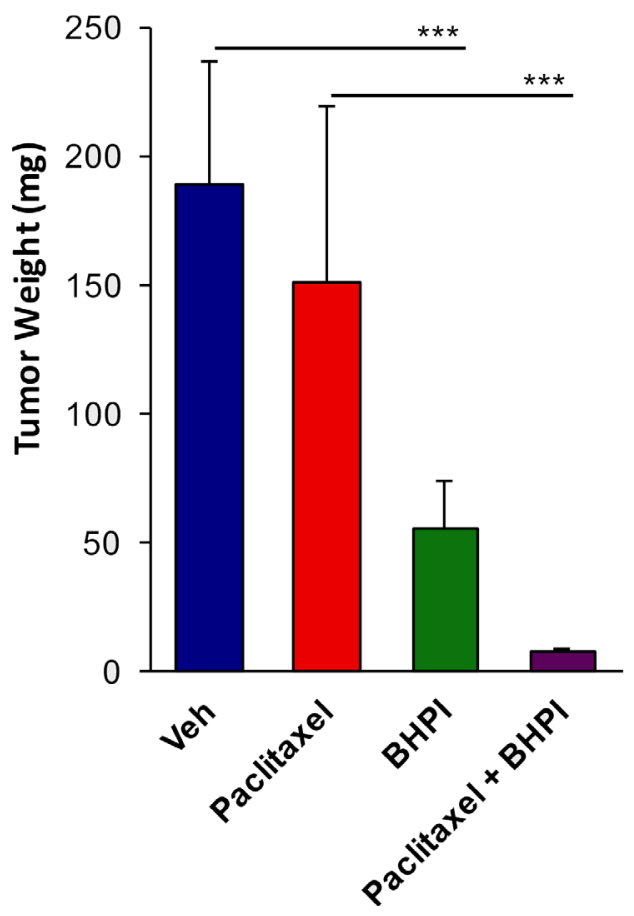

B

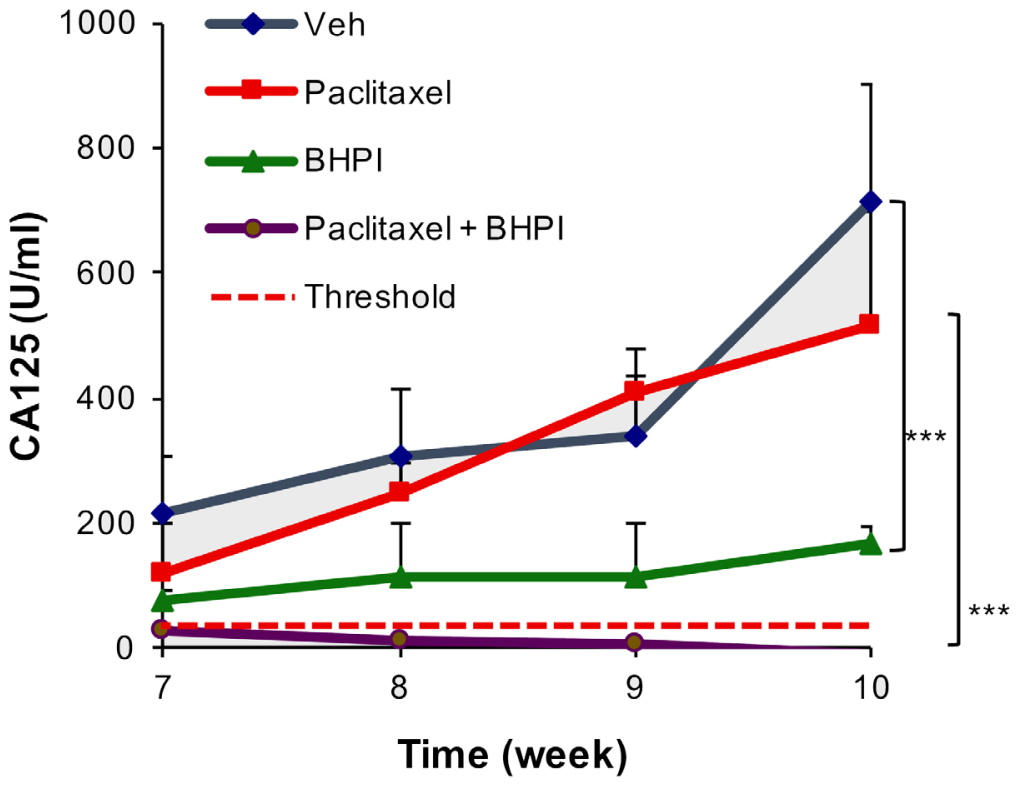

Figure 6: BHPI plus paclitaxel eliminates orthotopic multidrug resistant OVCAR-3 tumors. A. Average tumor weight from each treatment group $(n=5)$. For the paclitaxel group the secondary growths were included in tumor weight. B. Circulating serum CA125 biomarker quantitation showing the progression of tumors in each treatment group $(n=5)$. Threshold in humans (dashed line) denotes 35 $\mathrm{U} / \mathrm{ml}$ of circulating CA125. Data is the mean $\pm \mathrm{SEM} . * * * P<0.001$. 
ATP and inactivation of MDR1-mediated efflux (Figure $3 \mathrm{~A})$. Supporting the proposed pathway is our observation that BHPI is only effective in $\mathrm{ER}^{+}$cells. Furthermore, inhibitor and knockdown studies demonstrate the critical roles of PLC $\gamma, \mathrm{IP}_{3} \mathrm{R}$ calcium channels and SERCA pumps. BHPI-ER $\alpha$ hyperactivation of the UPR results in rapid depletion of ATP leading to activation of AMPK [18]. Activated AMPK reportedly inhibits MDR1 gene expression [51, 52]. Since together the potential AMPKmediated reduction in MDR1 gene expression and the UPR mediated inhibition of protein synthesis only reduce MDR1 protein levels $\sim 2$ fold, they are likely to be complementary, rather than central, to the dramatic and rapid reduction in MDR1 mediated efflux and to the restoration of drug sensitivity.

Despite MDR1's acute sensitivity to reduction in ATP levels therapeutic reduction of ATP levels has been an elusive target. The glyceraldehyde-3-phosphate dehydrogenase inhibitor, 3-bromopyruvate inhibits glycolysis, leading to loss of ATP and MDR1 inactivation [53]. However, lack of specificity, and toxicity in normal cells, have hindered therapeutic application of 3-bromopyruvate.

Ovarian cancers originate in the fallopian tubes or ovaries [5]. We used an orthotopic mouse xenograft model in which OVCAR-3 cells were grafted into the bursa of one ovary. Because these internal tumors cannot be directly measured until the study ends, serum levels of CA125 over the last 4 weeks of the study provide a surrogate marker for tumor progression. Serum CA125 levels in the paclitaxel and vehicle-treated mice increased rapidly in weeks 7-10. Tumor weight and CA125 levels indicated that the overall tumor burden was similar in the paclitaxel and vehicle-treated mice. Although the primary ovarian tumors were small in the paclitaxel-treated mice, these tumor-harboring mice were prone to developing large secondary (extra-ovarian) growths. Interestingly, increased metastasis following therapy has also been reported in prostate cancer xenografts treated with abiraterone [54] and breast cancer xenografts treated with sunitinib or bevacizumab [55]. CA125 levels and tumor weight were reduced $60-80 \%$ in the BHPI treated mice. The slight increase in CA125 levels in week 7-10 suggests BHPI strongly inhibited, but did not completely block, tumor progression. In contrast, in the BHPI plus paclitaxel treatment group, the already extremely low levels of CA125 at week 7 declined progressively to undetectable levels at week 10. This suggests ongoing tumor regression in this treatment group during the last 4 weeks of the study. Although there was substantial individual variation in tumor size and weight, and in CA125 levels, in the combined treatment group, both tumors and plasma CA125 were undetectable in all 5 mice. Absence of visible tumors, or complete loss of circulating tumor markers, has not been reported in other xenograft studies using highly drug-resistant OVCAR-3 ovarian cells [53, 56, 57].
De novo and acquired multidrug resistance is a core problem in cancer chemotherapy. In ovarian cancer, the primary driver of multidrug resistance is overexpression of MDR1. BHPI alone has emerged as a promising and well-tolerated therapeutic candidate for multidrug resistant ovarian cancer. Central to BHPI's therapeutic potential is its novel mechanism of action based on strong and sustained hyperactivation of the anticipatory UPR pathway, resulting in ATP depletion and MDR1 inactivation. This enables BHPI to resensitize multidrug resistant tumors to chemotherapeutic intervention and reduce ovarian tumor burden to undetectable levels. Thus, BHPI is a unique candidate for further mechanistic exploration and therapeutic development.

\section{MATERIALS AND METHODS}

\section{Cell culture and reagents}

Cell culture medium and conditions were as previously described $[18,32]$. Dr. S. Kaufmann provided PEO-4 ovarian cells. Dr. A. Parissenti provided MCF-7 and doxorubicin resistant MCF-7 (MCF-7 ${ }_{\text {dox }}$ ) breast cancer cells. OVCAR-3 cells were obtained from the ATCC. $\mathrm{E}_{2}$, U73122, Rhodamine-123 (Rho-123) dye and 2-amino propyl-benzoate (2-APB) were from Sigma Aldrich (St Louis, MO, USA). Ryanodine (Ry) was from Santa Cruz Biotechnology (Danvers, MA, USA). BHPI was synthesized on gram scale via a short sequence. Detailed experimental protocols are available in supplementary materials.

\section{Western blot}

Western blotting was carried out as previously described $[18,32,58]$. The following antibodies were used: Phospho-eIF2 $\alpha$ (Ser51) (\#3398; Cell Signaling Technology), eIF2 $\alpha$ (\#5324; Cell Signaling Technologies, MA), Phospho-PERK (\#3179; Cell Signaling Technology, MA), PERK (\#5683; Cell Signaling Technology, MA), ATF6 $\alpha$ (Imgenex, CA), PLC $\gamma$ (\#5690; Cell Signaling Technology, MA), BiP (\#3177; Cell Signaling Technology, MA), MDR1/ABCB1 (\#12683; Cell Signaling Technology, MA) and $\beta$-Actin (Sigma, MO). The protein and antibody complexes were detected using horseradish peroxidase-conjugated secondary antibodies and chemiluminescent immunodetection with an ECL Detection Kit (GE Healthcare, NJ), and were visualized using a PhosphorImager. 


\section{Cell proliferation assays}

Cells were plated in growth media with $10 \% \mathrm{CD}$ FBS for three days. Subsequently, cells were resuspended in growth media with $10 \% \mathrm{CD}$-calf serum and plated in 96 well plates. The medium was replaced with treatment media the following day, and plates were incubated at $37^{\circ} \mathrm{C}$ in $5 \% \mathrm{CO}_{2}$ for $2-4$ days. During experiments, the medium was replaced every two days. Cell number was determined using MTS and CellTiter 96 Aqueous One Solution Reagent (Promega). For each cell line, cell number was calculated from a standard curve of the number of plated cells at $\mathrm{A}_{490}$.

\section{Assaying MDR1 efflux activity}

Cells were plated in 6-well plates and allowed to reach $80 \%$ confluence. Subsequently, cells were loaded with $10 \mu \mathrm{M}$ of Rho-123 (1\% methanol, HBSS) for 10 minutes at $37^{\circ} \mathrm{C}$. Then, cells were washed three times with cold PBS to remove residual Rho-123 and efflux started by addition of pre-warmed HBSS buffer. At the end of the measured time points, cells were lysed with $2 \%(\mathrm{v} / \mathrm{v})$ triton-x100 in HBSS with proteinase inhibitor cocktail. Total protein was determined and Rho-123 concentration was normalized to total protein.

\section{Mouse xenografts}

All experiments were approved by the Institutional Animal Care Committee (IACUC) of the University of Illinois at Urbana-Champaign. The immunodeficient NSG mice (Jackson Laboratory) were obtained from in-house breeding. 1 million OVCAR-3 cells were orthotopically grafted into the bursa of one ovary. Subsequently, the mice were randomly divided into four treatment groups. Starting one week after injecting the tumor cells each group received vehicle plus vehicle, paclitaxel plus vehicle, vehicle plus BHPI, or paclitaxel plus BHPI. The paclitaxel was dissolved in Polysorbate- 80 and ethanol $(1: 1, \mathrm{vol} / \mathrm{vol})$ and further diluted with saline to reach final concentration. Stock BHPI was dissolved in DMSO and further diluted with $10 \%$ Tween-20 with $88 \%$ PBS to working concentration. Doses were $10 \mathrm{mg} / \mathrm{kg}$ of paclitaxel IP injected every other day, and $50 \mathrm{mg} / \mathrm{kg}$ of BHPI injected IP daily.

\section{Measuring levels of serum CA125}

Plasma CA125 concentrations were determined by ELISA according to the manufacturer's protocol (\#KA0205; Abnova, CA). The final serum CA125 concentrations were calculated based on a standard curve.
qRT-PCR, IP ${ }_{3}$ quantitation, PLC $\gamma$ siRNA knockdown, calcium imaging, and protein synthesis measurements

Carried out as we recently described [18, 32, 59].

\section{Statistical analysis}

$\mathrm{R}$ was used for the statistical analysis. For terminal tumor weights, one-way ANOVA followed by the KruskalWallis post hoc test was used $(P<0.05)$. For CA125 serum analysis, two-way ANOVA followed by Bonferroni's post hoc $t$-test was used $(P<0.05)$. Other analyses were conducted either with two-tailed Student $\mathrm{t}$ tests or with one-way ANOVA followed by Tukey post hoc tests $(P<$ $0.05)$. Data are reported as mean $\pm \mathrm{SEM}$.

\section{CONFLICTS OF INTEREST}

The authors declare no conflict of interest. Patent applications have been filed on BHPI.

\section{GRANT SUPPORT}

This work was supported by National Institutes of Health Grant RO1 DK-071909 (to D.S.) in part by Department of Defense Breast Cancer Research Program Grant W81XWH-13 (to D.S.) by institutional funds (to D.S. and E.N.), National Institutes of Health Grant R00 CA-172357 (to E.N.), NIH Chemistry-Biology Interface Training Grant NRSA 1-T32-GM070421 (to M.L.), and by a University of Illinois, Dept. of Biochemistry Predoctoral Fellowship (to X.Z. and N.A.).

\section{REFERENCES}

1. Kumar A, Le N, Santos J, Hoskins P. Chemotherapy is of Value in Second Line and Beyond, Relapsed Highgrade, Serous Epithelial Ovarian Cancer: An Analysis of Outcomes Obtained With Oral Etoposide. Am J Clin Oncol. 2016.

2. Romero I, Bast RC Jr. Minireview: human ovarian cancer: biology, current management, and paths to personalizing therapy. Endocrinology. 2012; 153:1593-1602.

3. Yap TA, Carden CP, Kaye SB. Beyond chemotherapy: targeted therapies in ovarian cancer. Nature reviews Cancer. 2009; 9:167-181.

4. Deroo BJ, Korach KS. Estrogen receptors and human disease. The Journal of clinical investigation. 2006; 116:561-570.

5. Sjoquist KM, Martyn J, Edmondson RJ, Friedlander ML. The role of hormonal therapy in gynecological cancerscurrent status and future directions. International journal of gynecological cancer. 2011;21:1328-1333. 
6. Spoerri M, Guscetti F, Hartnack S, Boos A, Oei C, Balogh O, Nowaczyk RM, Michel E, Reichler IM , Kowalewski MP. Endocrine control of canine mammary neoplasms: serum reproductive hormone levels and tissue expression of steroid hormone, prolactin and growth hormone receptors. BMC Vet Res. 2015; 11:235.

7. Bast RC Jr, Hennessy B, Mills GB. The biology of ovarian cancer: new opportunities for translation. Nature reviews Cancer. 2009; 9:415-428.

8. Montanari F, Ecker GF. Prediction of drug-ABC-transporter interaction-Recent advances and future challenges. Adv Drug Deliv Rev. 2015; 86:17-26.

9. Lawlor D, Martin P, Busschots S, Thery J, O'Leary JJ, Hennessy BT, Stordal B. PARP Inhibitors as P-glyoprotein Substrates. J Pharm Sci. 2014; 103:1913-1920.

10. Santos SA, Paulo A. Small molecule inhibitors of multidrug resistance gene (MDR1) expression: preclinical evaluation and mechanisms of action. Curr Cancer Drug Targets. 2013; 13:814-828.

11. Szakacs G, Paterson JK, Ludwig JA, Booth-Genthe C, Gottesman MM. Targeting multidrug resistance in cancer. Nat Rev Drug Discov. 2006; 5:219-234.

12. Kenicer J, Spears M, Lyttle N, Taylor KJ, Liao L, Cunningham CA, Lambros M, MacKay A, Yao C, ReisFilho J, Bartlett JM. Molecular characterisation of isogenic taxane resistant cell lines identify novel drivers of drug resistance. BMC Cancer. 2014; 14:762.

13. Patch AM, Christie EL, Etemadmoghadam D, Garsed DW, George J, Fereday S, Nones K, Cowin P, Alsop K, Bailey PJ, Kassahn KS, Newell F, Quinn MC, et al. Whole-genome characterization of chemoresistant ovarian cancer. Nature. 2015; 521:489-494.

14. Silva R, Vilas-Boas V, Carmo H, Dinis-Oliveira RJ, Carvalho F, de Lourdes Bastos M, Remiao F. Modulation of P-glycoprotein efflux pump: induction and activation as a therapeutic strategy. Pharmacology \& therapeutics. 2015; 149:1-123.

15. Horio M, Chin KV, Currier SJ, Goldenberg S, Williams C, Pastan I, Gottesman MM, Handler J. Transepithelial transport of drugs by the multidrug transporter in cultured Madin-Darby canine kidney cell epithelia. J Biol Chem. 1989; 264:14880-14884.

16. Inaba M, Kobayashi H, Sakurai Y, Johnson RK. Active efflux of daunorubicin and adriamycin in sensitive and resistant sublines of P388 leukemia. Cancer Res. 1979; 39:2200-2203.

17. Sarkadi B, Price EM, Boucher RC, Germann UA, Scarborough GA. Expression of the human multidrug resistance cDNA in insect cells generates a high activity drug-stimulated membrane ATPase. J Biol Chem. 1992; 267:4854-4858.

18. Andruska ND, Zheng X, Yang X, Mao C, Cherian MM, Mahapatra L, Helferich WG, Shapiro DJ. Estrogen receptor alpha inhibitor activates the unfolded protein response, blocks protein synthesis, and induces tumor regression. Proc Natl Acad Sci U S A. 2015; 112:4737-4742.

19. Wang M, Kaufman RJ. The impact of the endoplasmic reticulum protein-folding environment on cancer development. Nature reviews Cancer. 2014; 14:581-597.

20. Walter P, Ron D. The unfolded protein response: from stress pathway to homeostatic regulation. Science. 2011; 334:1081-1086.

21. Bravo R, Parra V, Gatica D, Rodriguez AE, Torrealba N, Paredes F, Wang ZV, Zorzano A, Hill JA, Jaimovich E, Quest AF, Lavandero S. Endoplasmic reticulum and the unfolded protein response: dynamics and metabolic integration. International review of cell and molecular biology. 2013; 301:215-290.

22. Shapiro DJ, Livezey M, Yu L, Zheng X, Andruska N. Anticipatory UPR Activation: A Protective Pathway and Target in Cancer. Trends in endocrinology and metabolism: TEM. 2016.

23. Zheng X, Andruska N, Yu L, Mao C, Kim JE, Livezey M, Helferich WG, Shapiro DJ. Interplay between steroid hormone activation of the unfolded protein response and nuclear receptor action. Steroids. 2016.

24. Monteith GR, McAndrew D, Faddy HM, Roberts-Thomson SJ. Calcium and cancer: targeting $\mathrm{Ca} 2+$ transport. Nature reviews Cancer. 2007; 7:519-530.

25. Papp B, Brouland JP. Altered Endoplasmic Reticulum Calcium Pump Expression during Breast Tumorigenesis. Breast cancer : basic and clinical research. 2011; 5:163-174.

26. Abdul M, Ramlal S, Hoosein N. Ryanodine receptor expression correlates with tumor grade in breast cancer. Pathology oncology research : POR. 2008; 14:157-160.

27. Lanner JT, Georgiou DK, Joshi AD, Hamilton SL. Ryanodine receptors: structure, expression, molecular details, and function in calcium release. Cold Spring Harbor perspectives in biology. 2010; 2:a003996.

28. Maxwell JT, Natesan S, Mignery GA. Modulation of inositol 1,4,5-trisphosphate receptor type 2 channel activity by $\mathrm{Ca} 2+/$ calmodulin-dependent protein kinase II (CaMKII)mediated phosphorylation. J Biol Chem. 2012; 287:3941939428.

29. Alonso MT, Manjarres IM, Garcia-Sancho J. Privileged coupling between $\mathrm{Ca}(2+)$ entry through plasma membrane store-operated $\mathrm{Ca}(2+)$ channels and the endoplasmic reticulum $\mathrm{Ca}(2+)$ pump. Molecular and cellular endocrinology. 2012; 353:37-44.

30. Arbabian A, Brouland JP, Gelebart P, Kovacs T, Bobe R, Enouf J, Papp B. Endoplasmic reticulum calcium pumps and cancer. BioFactors. 2011; 37:139-149.

31. Bublitz M, Musgaard M, Poulsen H, Thogersen L, Olesen C, Schiott B, Morth JP, Moller JV, Nissen P. Ion pathways in the sarcoplasmic reticulum Ca2+-ATPase. J Biol Chem. 2013; 288:10759-10765.

32. Andruska N, Zheng X, Yang X, Helferich WG, Shapiro DJ. Anticipatory estrogen activation of the unfolded protein 
response is linked to cell proliferation and poor survival in estrogen receptor alpha-positive breast cancer. Oncogene. 2015; 34:3760-3769.

33. Chen Y, Brandizzi F. IRE1: ER stress sensor and cell fate executor. Trends in cell biology. 2013; 23:547-555.

34. Gardner BM, Pincus D, Gotthardt K, Gallagher CM, Walter P. Endoplasmic reticulum stress sensing in the unfolded protein response. Cold Spring Harbor perspectives in biology. 2013; 5:a013169.

35. Korennykh A, Walter P. Structural basis of the unfolded protein response. Annu Rev Cell Dev Biol. 2012; 28:251277.

36. Hamilton TC, Young RC, McKoy WM, Grotzinger KR, Green JA, Chu EW, Whang-Peng J, Rogan AM, Green WR, Ozols RF. Characterization of a human ovarian carcinoma cell line (NIH:OVCAR-3) with androgen and estrogen receptors. Cancer Res. 1983; 43:5379-5389.

37. Kim HJ, Yim GW, Nam EJ, Kim YT. Synergistic Effect of COX-2 Inhibitor on Paclitaxel-Induced Apoptosis in the Human Ovarian Cancer Cell Line OVCAR-3. Cancer Res Treat. 2014; 46:81-92.

38. Guo B, Villeneuve DJ, Hembruff SL, Kirwan AF, Blais DE, Bonin M, Parissenti AM. Cross-resistance studies of isogenic drug-resistant breast tumor cell lines support recent clinical evidence suggesting that sensitivity to paclitaxel may be strongly compromised by prior doxorubicin exposure. Breast Cancer Res Treat. 2004; 85:31-51.

39. Reed K, Hembruff SL, Sprowl JA, Parissenti AM. The temporal relationship between $\mathrm{ABCB} 1$ promoter hypomethylation, $\mathrm{ABCB} 1$ expression and acquisition of drug resistance. Pharmacogenomics J. 2010; 10:489-504.

40. Forster S, Thumser AE, Hood SR, Plant N. Characterization of rhodamine-123 as a tracer dye for use in in vitro drug transport assays. PloS one. 2012; 7:e33253.

41. Yoshizawa Y, Ogawara K, Kimura T, Higaki K. A novel approach to overcome multidrug resistance: utilization of P-gp mediated efflux of paclitaxel to attack neighboring vascular endothelial cells in tumors. European journal of pharmaceutical sciences. 2014; 62:274-280.

42. Olszewski W, Pienkowski T, Olszewski W, Mrozkowiak A, Bauer-Kosinska B, Piascik A, Olszewska K, Wojnowska A, Michalski W. Topoisomerase 2alpha status in invasive breast carcinoma - comparison of its clinical value according to immunohistochemical and fluorescence in situ hybridization methods of evaluation. Pol J Pathol. 2014; 65:283-290.

43. Galluzzi L, Vitale I, Michels J, Brenner C, Szabadkai G, Harel-Bellan A, Castedo M, Kroemer G. Systems biology of cisplatin resistance: past, present and future. Cell Death Dis. 2014; 5:e1257.

44. Mitra AK, Davis DA, Tomar S, Roy L, Gurler H, Xie J, Lantvit DD, Cardenas H, Fang F, Liu Y, Loughran E, Yang J, Sharon Stack M, et al. In vivo tumor growth of high-grade serous ovarian cancer cell lines. Gynecologic oncology. 2015; 138:372-377.

45. Burbridge MF, Kraus-Berthier L, Naze M, Pierre A, Atassi G, Guilbaud N. Biological and pharmacological characterisation of three models of human ovarian carcinoma established in nude mice: use of the CA125 tumour marker to predict antitumour activity. Int J Oncol. 1999; 15:1155-1162.

46. Goodell CA, Belisle JA, Gubbels JA, Migneault M, Rancourt C, Connor J, Kunnimalaiyaan M, Kravitz R, Tucker W, Zwick M, Patankar MS. Characterization of the tumor marker muc16 (ca125) expressed by murine ovarian tumor cell lines and identification of a panel of crossreactive monoclonal antibodies. Journal of ovarian research. $2009 ; 2: 8$.

47. Zhang J, Chen X, Shi G, Xie X, Liu H, Zhang X, Lai Y, Zuo Y, Chen Z, Liu S, Wang H. Establishment of a new representative model of human ovarian cancer in mice. Journal of ovarian research. 2013; 6:9.

48. Spillman MA, Manning NG, Dye WW, Sartorius CA, Post MD, Harrell JC, Jacobsen BM, Horwitz KB. Tissue-specific pathways for estrogen regulation of ovarian cancer growth and metastasis. Cancer Res. 2010; 70:8927-8936.

49. Matsuo K, Sheridan TB, Mabuchi S, Yoshino K, Hasegawa K, Studeman KD, Im DD, Rosenshein NB, Roman LD, Sood AK. Estrogen receptor expression and increased risk of lymphovascular space invasion in high-grade serous ovarian carcinoma. Gynecologic oncology. 2014; 133:473479 .

50. van Kruchten M, van der Marel P, de Munck L, Hollema H, Arts H, Timmer-Bosscha H, de Vries E, Hospers G, Reyners A. Hormone receptors as a marker of poor survival in epithelial ovarian cancer. Gynecologic oncology. 2015; 138:634-639.

51. Kim HG, Hien TT, Han EH, Hwang YP, Choi JH, Kang KW, Kwon KI, Kim BH, Kim SK, Song GY, Jeong TC, Jeong HG. Metformin inhibits P-glycoprotein expression via the NF-kappaB pathway and CRE transcriptional activity through AMPK activation. British journal of pharmacology. 2011; 162:1096-1108.

52. Wang Z, Zhang L, Ni Z, Sun J, Gao H, Cheng Z, Xu J, Yin P. Resveratrol induces AMPK-dependent MDR1 inhibition in colorectal cancer HCT116/L-OHP cells by preventing activation of NF-kappaB signaling and suppressing cAMPresponsive element transcriptional activity. Tumour Biol. 2015; 36:9499-9510.

53. Xu RH, Pelicano H, Zhou Y, Carew JS, Feng L, Bhalla $\mathrm{KN}$, Keating MJ, Huang P. Inhibition of glycolysis in cancer cells: a novel strategy to overcome drug resistance associated with mitochondrial respiratory defect and hypoxia. Cancer Res. 2005; 65:613-621.

54. Vignani F, Bertaglia V, Buttigliero C, Tucci M, Scagliotti GV, Di Maio M. Skeletal metastases and impact of anticancer and bone-targeted agents in patients with castration-resistant prostate cancer. Cancer Treat Rev. 2016; 44:61-73. 
55. Conley SJ, Gheordunescu E, Kakarala P, Newman B, Korkaya H, Heath AN, Clouthier SG, Wicha MS. Antiangiogenic agents increase breast cancer stem cells via the generation of tumor hypoxia. Proc Natl Acad Sci U S A. 2012; 109:2784-2789.

56. Kenmogne LC, Ayan D, Roy J, Maltais R, Poirier D. The Aminosteroid Derivative RM-133 Shows In Vitro and In Vivo Antitumor Activity in Human Ovarian and Pancreatic Cancers. PloS one. 2015; 10:e144890.

57. Pourgholami MH, Mekkawy AH, Badar S, Morris DL. Minocycline inhibits growth of epithelial ovarian cancer. Gynecologic oncology. 2012; 125:433-440.

58. Cheng J, Zhang C, Shapiro DJ. A functional serine 118 phosphorylation site in estrogen receptor-alpha is required for down-regulation of gene expression by 17 beta-estradiol and 4-hydroxytamoxifen. Endocrinology. 2007; 148:46344641 .
59. Yu L, Andruska N, Zheng X, Shapiro DJ. Anticipatory activation of the unfolded protein response by epidermal growth factor is required for immediate early gene expression and cell proliferation. Molecular and cellular endocrinology. 2015. 